\title{
Analysis of the Color Coordinates Change of Textile as a Function of Knitting Transformation: Effect of Some Parameters and Mathematical Modelling
}

\author{
Zouhaier Romthani $^{1,2}$, Sabri Halaoua ${ }^{2}$, Mohamed Hamdaoui ${ }^{2}$ \\ ${ }^{1}$ Laboratory of Interfaces and Advanced Materials, FSM, University of Monastir, Tunisia \\ ${ }^{2}$ Textile Materials and Process Research Unit, ENIM, University of Monastir, Tunisia
}

\begin{abstract}
The present paper provides a systematic analysis on the character of color change from the transformation of dyed yarn into knitted fabric. First, the cotton yarn was dyed with Lavafix Brillant Red E4BA (a reactive dye) and Polyazo dye Solophenyl Red 3BL (a direct dye) with three nuances (1, 2 and 3\%). Then two knitted structure were produced (rib 1x1 and single jersey). Further three couliering depths (11,13 and 15) were varied during the manufacture of the knit fabric. The change of the color was analyzed via the measurement of the colorimetric coordinates $\left(\mathrm{L}^{*}, \mathrm{a}^{*}, \mathrm{~b}^{*}\right)$. The experimental results were modeled using a typical mathematical matrix of transformation. The color degradation of the rib $1 \mathrm{x} 1$ structure was very significant than that observed for the single jersey. As generally observed, the machine influences more strongly the degradation of the direct dye than the reactive one. This could be explained by the fixing process of the dye on the cotton yarn. As the change in color coordinates is very significant in the textile industry, this work could offer a new useful typical mathematical tool to study the influence of different parameters of knitting operation on color change.
\end{abstract}

Keywords: color coordinates; yarn; knitted structure; direct and reactive dye, mathematical modelling

\section{INTRODUCTION}

Recently, knitted fabrics have received great attention in different industrial domains. For example, in clothing industry, people look ahead to higher comfort from their [1, 2]. Compared to woven structures, knit fabric can be more easily deformed or stretched by facile compression or elongation [3]. Knit fabrics possess comfort with the shape of the body, softness, good feeling of freshness, air permeability and heat insulation. Indeed, the knitting of yarn depends on its strength and frictional properties [4]. It has, also, been proved that the change in yarn friction affects the loop length. This was explained by the phenomenon of Robbing [5]. It has also explained that the variation of the gauge makes an asymmetry of the stitch. This can produces a permanent deformation and the relaxation doesn't appear sufficient to eliminate this disorder.

Additionally, the influence of some knitting parameters on the mechanism of loop formation has been studied in the literature [6-8]. It appears that the resistance of textile fabrics is based on several parameters such as the mechanical properties of the fibers, their dimensions, the structure of the yarns, the construction of the fabrics, the type and kind of finishing material, etc. [9]. Moreover, the cam setting is considered as the primary parameter among all machine settings that influences the knitting phenomenon and the fabric properties [10,11]. As a consequence, the necessity to satisfy the requirements of the customers imposes a permanent vigilance and a continuous control of the textile products. More importantly, the nuance of the finished product is influenced by all chemical or mechanical including the knitting operations. Many problems influence the color quality such as the fiber characteristics, the parameters of manufacture and the textile structure itself [12]. The color change is also influenced by some other additional factors such as temperature, friction, water and atmosphere. The mechanical color change implies alteration of textile material. The friction and the lint shedding affect greatly the knitting performance. The rubbing property of yarn-needle affects the knitting of yarn. It affects the yarn tension and the high friction can increases the abrasion of yarn with knitting elements and guides. Hence, experimental studies have been conducted to find out the effect of yarn-yarn and yarn-metal rubbing, yarn input tension, cam setting and yarn properties on loop length and on yarn tension profile [13-15]. 
Zouhaier Romthani et al. "Analysis of the Color Coordinates Change of Textile as a Function of Knitting Transformation: Effect of Some Parameters and Mathematical Modelling"

In line with this fundamental topic, and to our knowledge, the color change or degradation during the knitting operation starting from a same dyed yarn was seldom studied in the literature. For example in their research, Choi \& Powell [16], showed a new analysis and interpretation of conventional tiedfabric resist methods by incorporating advanced knitting technology. In other work, the aim of the works of Mumtaz \& Tanveer [17] was to assess the effect of the percentage of short cotton fibers removed during spinning on the properties of dyed polyester/cotton blended knitted fabrics. Herein, our present contribution, deals with a discussing of the color changes and degradation of the dyed yarn after its knitting operation. The influence of the dye structure itself, the couliering depth and the nuance on the color degradation of either rib1 1 or single jersey knitted fabrics were studied in terms of color coordinates change. Then a typical mathematical modeling describing this change in color in the obtained knitting structure changes was developed via a matrix of transformation.

\section{MATERIALS AND METHODS}

\section{Materials}

Yarn 100\% cotton $(40 \mathrm{Nm})$ was provided from SITEX (Société des Industries Textiles, Sousse, Tunisie). The direct dye solo phenyl $3 \mathrm{BL}$ and the reactive dye Levafix Brillant E4BA were supplied from Sigma Aldrich. Their chemical structures were given in Figure 1. All reagents such as hydrogen peroxide $(35 \%)$, sodium carbonate and sodium silicate are commercially available.

(a)

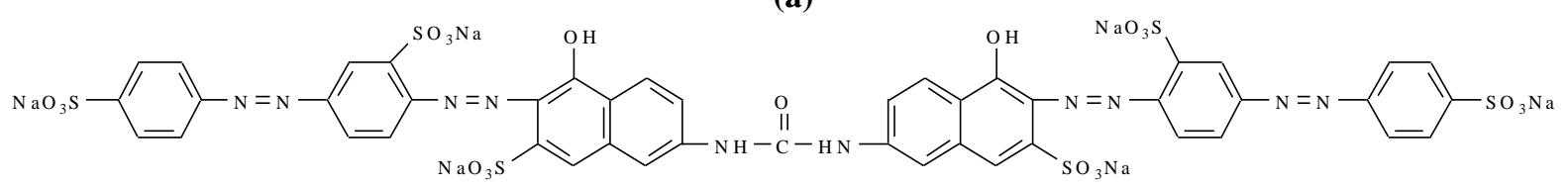<smiles>N#Cc1cc2cc(S(N)(=O)=O)cc(NC(=O)c3ccccc3)c2c(O)c1N=Nc1ccc2c(CNc3nc(F)nc(F)c3Cl)cccc2c1[N+]([O-])([O-])O</smiles>

Figure1. Chemical structure of the used dyes: (a) Polyazo dye Solophenyl Red 3BL and (b) Lavafix Brillant Red $E 4 B A$

\section{Preparation of the Textile and Dyeing Procedure}

Cotton yarn was bleached in a solution containing $4 \mathrm{~mL} / \mathrm{L}$ hydrogen peroxide (35\%), $2 \mathrm{~g} / \mathrm{L}$ sodium carbonate and $2 \mathrm{~g} / \mathrm{L}$ stabilizer (sodium silicate) in order to obtain an hydrophilic structure exempt of impurities. The dyeing processes were carried out in a laboratory apparatus (AHIBA Nuance, Data Color). For the direct dyeing [(Figure 2(a)], the yarn $(5 \mathrm{~g})$ was placed in the bath containing $1 \%$ of sodium carbonate, $20 \%$ of salt with different required amount of dye $(1 \%, 2 \%$ and $3 \%)$ in $200 \mathrm{~mL}$ water. Experiments were conducted for 10 minutes at $40^{\circ} \mathrm{C}$. Then, the temperature of the bath was increased to $80^{\circ} \mathrm{C}$ during 30 minutes. Dyeing was kept during 50 minutes at $90^{\circ} \mathrm{C}$. Finally, the yarn was rinsed with hot and cold water.

Whereas, for the reactive dye [(Figure 2(b)], a same mass of yarn was placed in a bath containing $1 \mathrm{~g} / \mathrm{L}$ of sequestrating solution in $200 \mathrm{~mL}$ water and dispersed for 10 minutes at $40^{\circ} \mathrm{C}$. Then, the required amount of salt was added. The temperature was increased at $60^{\circ} \mathrm{C}$ during 20 minutes and the sodium carbonate was added. The temperature was kept for 60 minutes in this stage. The liquor was then drained and refilled and soaping off was performed at $90^{\circ} \mathrm{C}$ with $0.5 \mathrm{~g} / \mathrm{L}$ of dispersant. Finally, the liquor was drained and refilled to allow neutralization with $0.25 \mathrm{~g} / \mathrm{L}$ acetic acid and $2 \mathrm{~g} / \mathrm{L}$ Softener to apply a softness treatment at $50^{\circ} \mathrm{C}$ for 5 minutes. All samples were then left to air dry in a cabinet dryer. 
Zouhaier Romthani et al. "Analysis of the Color Coordinates Change of Textile as a Function of Knitting Transformation: Effect of Some Parameters and Mathematical Modelling”

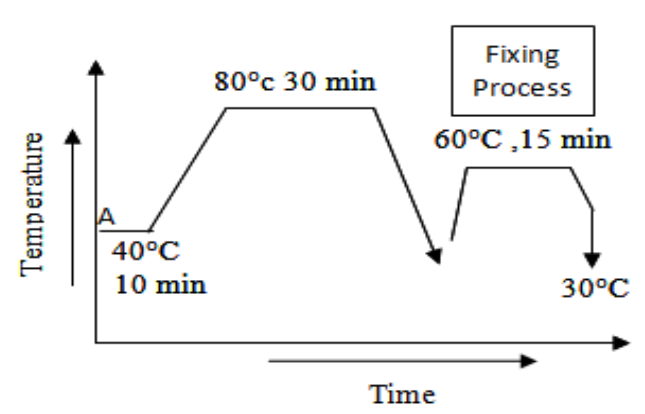

(a)

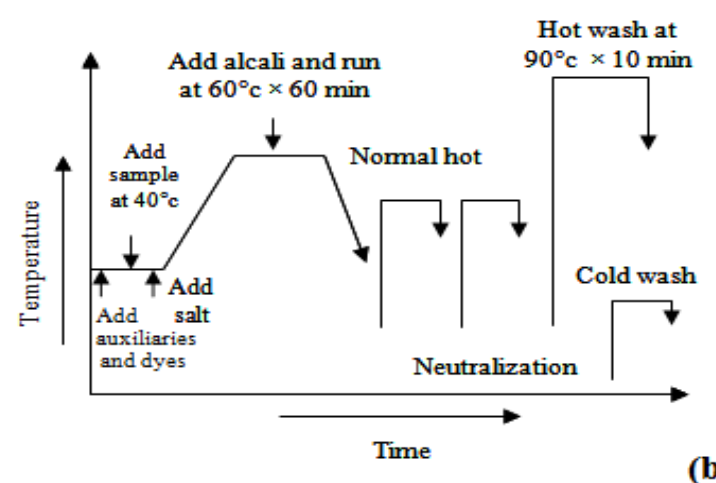

(b)

Figure2. Process of dyeing of cotton with: (a) Polyazo dye Solophenyl Red 3BL and (b) Lavafix Brillant Red $E 4 B A$

\section{Transformation of Yarn to Knitted Fabric}

The dyed yarns were used as starting products to produce a series of rib $1 \mathrm{x} 1$ and single jersey knits using an industrial double jersey Hand Driven Flat Knitting Machine. In attempts to analyze the influence of the couliering depth on the color change as a function of knitting transformation, three values were checked 11,13 and 15 .

\section{Colorimetric Measurements}

The color coordinates of textile materials before and after knitting operation were measured using the $L^{*}, a^{*}, b^{*}$ coordinates of the CIE [Commission International d'Eclairage, 1976] color space. Three parameters were, therefore, recorded; chromaticity parameters [a* (red-green) and $b^{*}$ (yellow-blue)] and the lightness $\left(\mathrm{L}^{*}\right)$. Measurements were carried out using a SpectroFlash SF600 spectrophotometer with dataMaster 2.3 software (Datacolor International, USA).

\section{Theory of Mathematical Modelling}

The color coordinates of the dyed yarns were abbreviated as $\mathrm{L}_{\mathrm{y}}{ }^{*}, \mathrm{a}_{\mathrm{y}}{ }^{*}, \mathrm{~b}_{\mathrm{y}}{ }^{*}$, (illuminant $\mathrm{D} 65 / 10^{\circ}$ observer). For each sample, the mean value of three measurements was registered. The transformations of the structure from yarns to knitted fabrics were analyzed and the new color coordinates of the knitted fabric were assessed as $\mathrm{L}_{\mathrm{f}}{ }^{*}, \mathrm{a}_{\mathrm{f}}{ }^{*}, \mathrm{~b}_{\mathrm{f}}{ }^{*}$. Using the color coordinate values of dyed yarns structure $\left(\mathrm{L}_{\mathrm{y}}{ }^{*}, \mathrm{a}_{\mathrm{y}}{ }^{*}, \mathrm{~b}_{\mathrm{y}}{ }^{*}\right)$ and knit fabrics structure $\left(\mathrm{L}_{\mathrm{f}}{ }^{*}, \mathrm{a}_{\mathrm{f}}{ }^{*}, \mathrm{~b}_{\mathrm{f}}{ }^{*}\right)$, we measure the change in color as a result of the transformations of the structure form yarns to knitted fabrics. The change in color coordinates was then evaluated. Mathematically, this is most easily performed using a 3-by-3 matrix of color changes of the following form:

$$
\left(\begin{array}{l}
L_{f}^{*} \\
a_{f}^{*} \\
b_{f}^{*}
\end{array}\right)=\left(\begin{array}{lll}
n_{11} & n_{12} & n_{13} \\
n_{21} & n_{22} & n_{23} \\
n_{31} & n_{32} & n_{33}
\end{array}\right)\left(\begin{array}{c}
L_{y}^{*} \\
a_{y}^{*} \\
b_{y}^{*}
\end{array}\right)
$$

Where:

nij: represents the element at the $\mathrm{i}$ row and $\mathrm{j}$ column of the matrix., $\mathrm{L}_{\mathrm{y}}{ }^{*}, \mathrm{a}_{\mathrm{y}}{ }^{*}$ and $\mathrm{b}_{\mathrm{y}}{ }^{*}$ represents the Lightness-darkness; the red-Green value and the yellow-blue value, respectively. If all the elements on the main diagonal are equal to 1 and all other elements are equal to 0 , the equation (1) could be be rewritten as follows:

$$
\left(\begin{array}{l}
L_{f}^{*} \\
a_{f}^{*} \\
b_{f}^{*}
\end{array}\right)=\left(\begin{array}{lll}
1 & 0 & 0 \\
0 & 1 & 0
\end{array}\right)\left(\begin{array}{c}
L_{y}^{*} \\
a_{y}^{*} \\
b_{y}^{*}
\end{array}\right)
$$


Zouhaier Romthani et al. "Analysis of the Color Coordinates Change of Textile as a Function of Knitting Transformation: Effect of Some Parameters and Mathematical Modelling"

In this case, when the matrix of the dyed structure transformation (from yarn to knit fabric) is equal to the identity matrix, it is evident that there is no degradation of color. So, in attempts, to evaluate the loss of the color as a result of the transformations of the structure from yarns to knitted fabrics, it is useful to measure the evolution of the colorimetric coordinates $\mathrm{L}^{*}, \mathrm{a}^{*}, \mathrm{~b}^{*}$ associated with these two structures. This needs the determination of the matrix elements ( $n i j)$.

Indeed, the equation (1) is a matrix multiplication where the nij represent the unknowns. Conventionally, we can express the equation (1) as follows:

$$
\left\{\begin{array}{l}
L_{f}^{*}=n_{11} L_{y}^{*}+n_{12} a_{y}^{*}+n_{13} b_{y}^{*} \\
a_{f}^{*}=n_{21} L_{y}^{*}+n_{22} a_{y}^{*}+n_{23} b_{y}^{*} \\
b_{f}^{*}=n_{31} L_{y}^{*}+n_{32} a_{y}^{*}+n_{33} b_{y}^{*}
\end{array}\right.
$$

By solving equation 3, this allows us to determine the matrix elements (nij)

\section{RESULTS AND DISCUSSION}

\section{Effect of the Nature of Dye on the Color Change after Knitting Transformation}

Various knitted fabric samples have been produced using double jersey flat knitting machines, from the same nature of yarn. To do this, the dyed yarns with no intermediate winding (no lubricant was used), were knitted in two structures (the single jersey and the rib 1x1) obtained using three different couliering depth of 11,13 and 15.

Table 1 summarizes the color characteristics $\left(\mathrm{L}_{\mathrm{y}}{ }^{*}, \mathrm{a}_{\mathrm{y}}{ }^{*}, \mathrm{~b}_{\mathrm{y}}{ }^{*}\right)$ of the yarns dyed with the direct and reactive dyes. As observed, the color coordinates varies as a function of not only the nature of dye but also against the content of dye (nuance).

Table1. Color coordinates characteristics of the dyed yarns

\begin{tabular}{|l|l|l|l|l|}
\hline Dye & Dye conc. $(\%)$ & $\mathrm{L}_{\mathrm{y}}{ }^{*}$ & $\mathrm{a}_{\mathrm{y}}{ }^{*}$ & $\mathrm{~b}_{\mathrm{y}}{ }^{*}$ \\
\hline \multirow{4}{*}{ Direct } & 1 & 46,55 & 52,23 & 12,00 \\
\cline { 2 - 5 } & 2 & 44,76 & 52,85 & 13,16 \\
\cline { 2 - 5 } & 3 & 40,74 & 52,36 & 14,76 \\
\hline \multirow{3}{*}{ Reactive } & 1 & 48,49 & 55,56 & 23,37 \\
\cline { 2 - 5 } & 2 & 45,82 & 57,41 & 27,09 \\
\cline { 2 - 5 } & 3 & 42,45 & 57,18 & 29,10 \\
\hline
\end{tabular}

Table 2 summarizes the color characteristics $\left(\mathrm{L}_{\mathrm{f}}{ }^{*}, \mathrm{a}_{\mathrm{f}}{ }^{*}, \mathrm{~b}_{\mathrm{f}}{ }^{*}\right)$ of the knitted fabric obtained from the direct and reactive dyed yarn. It is well observed that the knitting transformation affects the color of the start material. For example, for the start yarn dyed with a direct dye (1\%), the lightness value passes from 46,55 to 43,53 when producing a Rib $1 \times 1$ with a couliering depth of 11 . Whereas, for the yarn dyed with a reactive dye (1\%), this value varies from 48,49 to 41,12 in the same conditions of yarn transformation.

Table2. Color coordinates characteristics of Rib $1 x 1$ dyed with reactive and direct dye

\begin{tabular}{|c|c|c|c|c|c|c|}
\hline Pattern & Dye & Couliering depth & Dye conc. $(\%)$ & $\mathrm{L}_{\mathrm{f}}^{* *}$ & $a_{\mathrm{f}}{ }^{*}$ & $b_{f}^{*}$ \\
\hline \multirow{12}{*}{ Rib $1 \times 1$} & \multirow{9}{*}{ Direct } & \multirow{3}{*}{11} & 1 & 43,53 & 50,68 & 11,17 \\
\hline & & & 2 & 41,77 & 50,88 & 12,76 \\
\hline & & & 3 & 40,04 & 54,43 & 14,04 \\
\hline & & \multirow{3}{*}{13} & 1 & 42,98 & 49,86 & 10,02 \\
\hline & & & 2 & 42,27 & 50,67 & 11,80 \\
\hline & & & 3 & 39,26 & 54,41 & 14,00 \\
\hline & & \multirow{3}{*}{15} & 1 & 41,10 & 48,52 & 9,41 \\
\hline & & & 2 & 40,05 & 50,43 & 11,34 \\
\hline & & & 3 & 39,15 & 54,05 & 13,81 \\
\hline & \multirow{3}{*}{ Reactive } & \multirow{3}{*}{11} & 1 & 41,12 & 53,80 & 23,27 \\
\hline & & & 2 & 40,17 & 53,97 & 25,68 \\
\hline & & & 3 & 39,08 & 50,98 & 28,02 \\
\hline
\end{tabular}


Zouhaier Romthani et al. "Analysis of the Color Coordinates Change of Textile as a Function of Knitting Transformation: Effect of Some Parameters and Mathematical Modelling"

\begin{tabular}{|l|l|l|l|l|l|l|}
\hline & \multirow{3}{*}{13} & 1 & 40,02 & 53,61 & 22,37 \\
\cline { 3 - 7 } & & 2 & 39,84 & 54,00 & 25,40 \\
\cline { 3 - 7 } & & 3 & 37,54 & 50,96 & 27,97 \\
\cline { 3 - 7 } & \multirow{3}{*}{15} & 1 & 39,49 & 53,26 & 22,31 \\
\cline { 3 - 7 } & & 2 & 38,55 & 53,71 & 24,17 \\
\cline { 3 - 7 } & & 3 & 37,39 & 49,47 & 25,46 \\
\hline
\end{tabular}

\section{Effect of the Nuance on the Color Change after Knitting Transformation}

In Figure 3, we give the percentage of fall of luminosity of rib1x 1 and single jersey knitted structure. The high value in color change was obtained for a percentage of 3\% of dye for the two textile structures. More importantly, the rib 1x1 exhibits the important color degradation. This could be explained based on the rubbing of the needles where the surface of contact yarn-needle is very important. Consequently, the yarn undergoes a big rubbing. So, the reduction of the lightness value is directly related to the contact surface yarn-needle.

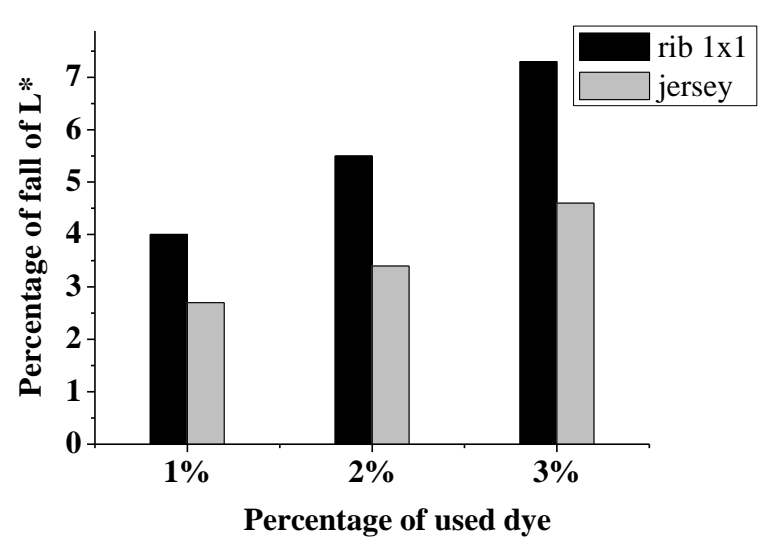

Figure3. The variation of the lightness according to the percentage of used nuance

\section{Effect of the Couliering Depth}

In attempts to analyze the influence of the couliering depth on the color change as a function of knitting transformation, this parameter was studied and results were given in Figure 4. While increasing the couliering depth, the stitch size increases therefore important length of the absorbed yarn was obtained. Compared to the yarn, the most important variation of the luminosity was obtained for the couliering depth 15 for both knitted structure. So increasing the stitch, the surface of contact yarn-needle becomes bigger which leads to the dye degradation.
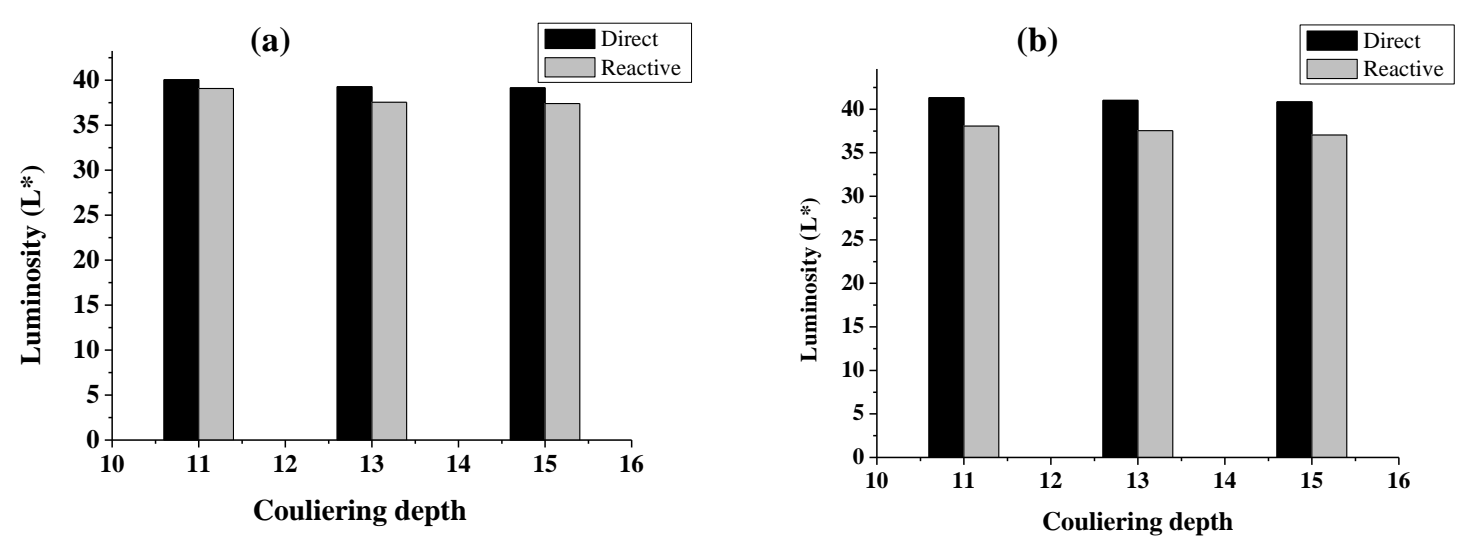

Figure4. Effect of the couliering depth on the luminosity value change: (a) rib $1 * 1$ fabric and (b) jersey fabric $(\%$ dye $=3 \%)$ 
Zouhaier Romthani et al. "Analysis of the Color Coordinates Change of Textile as a Function of Knitting Transformation: Effect of Some Parameters and Mathematical Modelling"

In table 3, we summarize all color coordinates values for the reactive and direct dyeing performed on either Rib $1 * 1$ or Jersey.

Table3. Variation of the color coordiantes as a function of knitting tranformation for the dyeing with reactive and direct dye

\begin{tabular}{|c|c|c|c|c|c|}
\hline Pattern & Dye & Couliering depth & $\mathrm{L}_{\mathrm{f}}^{*}$ & $a_{f}^{*}$ & $b_{f}^{*}$ \\
\hline \multirow{6}{*}{$\operatorname{Rib} 1 * 1$} & \multirow{3}{*}{ Direct } & 11 & 40,04 & 54,43 & 14,04 \\
\hline & & 13 & 39,26 & 54,41 & 14,00 \\
\hline & & 15 & 39,15 & 54,05 & 13,81 \\
\hline & \multirow{3}{*}{ Reactive } & 11 & 39,08 & 50,98 & 28,02 \\
\hline & & 13 & 37,54 & 50,96 & 27,97 \\
\hline & & 15 & 37,39 & 49,47 & 27,46 \\
\hline \multirow{6}{*}{ Jersey } & \multirow{3}{*}{ Direct } & 11 & 41,32 & 53,84 & 13,03 \\
\hline & & 13 & 41,01 & 53,07 & 12,61 \\
\hline & & 15 & 40,84 & 52,09 & 12,02 \\
\hline & \multirow{3}{*}{ Reactive } & 11 & 38,07 & 50,57 & 29,04 \\
\hline & & 13 & 37,53 & 49,47 & 28,22 \\
\hline & & 15 & 37,05 & 48,83 & 27,78 \\
\hline
\end{tabular}

Modeling of the Colour Change of Textile as a Function of Knitting Transformation

Using equation (3), we can determine the matrix analyzing the changes in color as a result of the transformation of the structure form yarns to knitted fabrics. It is called to us matrix of color changes. For example, the changes in color as a result of the transformation of the direct dyed yarns to the rib $1 \mathrm{x} 1$ knit using a couliering depth of 11 can be written as:

$$
\begin{aligned}
& 42.53=n_{11} 46.55+n_{12} 52.23+n_{13} 12.00 \\
& 50.68=n_{21} 46.55+n_{22} 52.23+n_{23} 12.00 \\
& 11.17=n_{31} 46.55+n_{32} 52.23+n_{33} 12.00 \\
& 43.77=n_{11} 44.76+n_{12} 52.85+n_{13} 13.16 \\
& 50.88=n_{21} 44.76+n_{22} 52.85+n_{23} 13.16 \\
& 12.76=n_{31} 44.76+n_{32} 52.85+n_{33} 13.16 \\
& 39.08=n_{11} 40.74+n_{12} 52.36+n_{13} 14.76 \\
& 50.98=n_{21} 40.74+n_{22} 52.36+n_{23} 14.76 \\
& 14.04=n_{31} 40.74+n_{32} 52.36+n_{33} 14.76
\end{aligned}
$$

\begin{tabular}{|c|c|c|c|c|c|c|}
\hline Couliering depth & \multicolumn{3}{|c|}{ Direct Dye } & \multicolumn{3}{|c|}{ Reactive Dye } \\
\hline \multirow[t]{3}{*}{11} & ( 1.17897 & -0.554488 & 1.38167 & $(-22.2002$ & 34.6121 & -342517 \\
\hline & -0.157433 & 1.82886 & -0.561227 & -28.0169 & 62.8989 & -41.5557 \\
\hline & -0.450571 & 0.580903 & 0.151127 & -13.9664 & 20.9424 & $-19.8151)$ \\
\hline \multirow[t]{3}{*}{13} & / 1.10962 & -0.504324 & $1.39068)$ & $(-18.8122$ & 29.6055 & -29.3831 ) \\
\hline & -0.464093 & 1.7362 & -1.594 & -37.186 & 57.578 & -55.0601 \\
\hline & -0.454586 & 0.577243 & 0.145965 & $(-11.2706$ & 16.8263 & -20.6613 \\
\hline
\end{tabular}

By solving this equations system, we can determine the matrix elements (nij). In this case, the matrix of the color change can be written as:

$$
\left(\begin{array}{l}
L_{f}^{*} \\
a_{f}^{*} \\
b_{f}^{*}
\end{array}\right)=\left(\begin{array}{ccc}
1.17897 & -0.554488 & 1.38167 \\
-0.157433 & 1.82886 & -0.561227 \\
-0.450571 & 0.580903 & 0.151127
\end{array}\right)\left(\begin{array}{c}
L_{y}^{*} \\
a_{y}^{*} \\
b_{y}^{*}
\end{array}\right)
$$

All systems are solved according to different parameters and diverse matrix elements were obtained. Table 4 shows the matrix of color changes of the knitted fabric obtained from the direct and reactive dyed yarn, according to the three used couliering depth.

Table4. Matrix of the color change of direct and reactive dyes 
Zouhaier Romthani et al. "Analysis of the Color Coordinates Change of Textile as a Function of Knitting Transformation: Effect of Some Parameters and Mathematical Modelling"

\begin{tabular}{|l|ccc|ccc|}
\hline 15 & $\left(\begin{array}{ccc}0.666785 & -0.108392 & 0.316652 \\
-0.431013 & 1.56753 & -0.06739 \\
-0.535691 & 0.705826 & 0.124491\end{array}\right)$ & $\left(\begin{array}{ccc}-38.0317 & 58.2709 & -57.6773 \\
-35.8207 & 54.5322 & -53.0441 \\
-28.6967 & 42.8947 & -41.4825\end{array}\right)$ \\
\hline
\end{tabular}

The degradation of the color can be, hence, judged in terms of the variation of the values $n_{11}, n_{22}$ and $\mathrm{n} 33$ of the matrix of colour change. These factors are the most important elements in the matirix which describe the principle variation of the color characteristics $\left(L^{*}, a^{*}, b^{*}\right)$. From table 4 , results reveal an important variation of different color variable. The difference of lightness value between the two textile structure was depicted. For example for the three couliering depth, the direct and the reactive dye have successively the $\mathrm{n} 11$ values of lightness variation between yarn and fabric:

\section{$1.17897>1.10962>0.666785$ and for the reactive dye $-22.2002>-28.8122>-38.0317$}

First, the increase of the couliering depth leads to a decrease of the nii which means that the lightness of the fabric decreases (table 4). As the weft knitting rib 1x1 was manufactured on two sets of needles operating at right angles to each other, this result may be explained not only by the increasing of opacity while varing the couliering depth but also by the effect of the needle on the surface of dyed yarn. Therefore, as a function of increasing couliering depth, the loop is very smaller and the contact surface of needle-yarn becomes very important, so the surface of rubbing increases which affect deeply the yarn colour.

Table5. The important factors of the matrix of color change for knitted fabric riblx1

\begin{tabular}{|c|c|c|c|c|}
\hline \multirow{2}{*}{ Dye } & \multirow{2}{*}{$\begin{array}{l}\text { Important factors of the matrix of } \\
\text { color change }\end{array}$} & \multicolumn{3}{|c|}{ Couliering depth } \\
\hline & & 11 & 13 & 15 \\
\hline \multirow{3}{*}{ Direct Dye } & $n_{11}$ & 1,17897 & 1,10962 & 0,666785 \\
\hline & $n_{22}$ & 1,82886 & 1,7362 & 1,56753 \\
\hline & $n_{33}$ & 0,151127 & 0,145965 & 0,124491 \\
\hline \multirow{3}{*}{ Reactive Dye } & $n_{11}$ & $-22,2002$ & $-28,8122$ & $-38,0317$ \\
\hline & $n_{22}$ & 62,8989 & 57,578 & 54,5322 \\
\hline & $n_{33}$ & $-19,8151$ & $-20,6613$ & $-41,4825$ \\
\hline
\end{tabular}

Generally, the machine influences more strongly the degradation of the direct dye that the reactive dye. This phenomenon could be explained by the fixing process of the dye on the cotton yarn. In fact, the molecules of reactive dyes are smaller than those of direct dyes. Hence, during dyeing, the functional groups of the reactive dye form covalent bond with polymer and become an integral part of the fiber. Reactive dye gives brighter shades and has moderate rubbing strength. For different other color characteristics $\left(a^{*}\right.$ and $\left.b^{*}\right)$, the matrix of color changes reveal the same influence on these parameters.

\section{CONCLUSION}

To sum up, this study was undertaken in order to analyze and determine quantitatively the effect of the knitting operation parameters on the color change of the dyed yarn after knitting transformation using a typical mathematical model. The effect of dye, couliering depth and nuance on the color degradation of rib1x1 and single jersey knitted fabrics were discussed in terms of $\mathrm{L}^{*}, \mathrm{a}^{*}, \mathrm{~b}^{*}$ coordinates change. According to the experimental results, it was proved that the variation of the color after knitting operation of rib $1 \times 1$ on flat machine depends on the couliering depth. As a consequence, the increase in this factor leads to the decrement in color change. The nature of dye it-self affects deeply the color change after knitting operation. Direct dyeing was found to be the most color changed than the reactive one. This was explained by the fixing process and power of the link energy between the dye and the fiber. Further works will be extended for the analysis of other structure of knitting via the developed mathematical model and using other class of dyes.

\section{REFERENCES}

[1] Marguerite E. S., Lawrance H., \& Anton B., 2015,. The Effect of Fabric Structural Parameters and Fiber Type on the Comfort-Related Properties of Commercial Apparel Fabrics. Journal of Natural Fibers. 12, 505-517.

[2] Y. Li., 2001, The science of clothing comfort. Textile progress, 31, 1-135. 
Zouhaier Romthani et al. "Analysis of the Color Coordinates Change of Textile as a Function of Knitting Transformation: Effect of Some Parameters and Mathematical Modelling"

[3] Sadek, R., El-Hossini, A. M., Eldeeb, A. S. \& Yassen, A.A., 2012, Effect of Lycra Extension Percent on Single Jersey Knitted Fabric Properties. Journal of Engineered Fibers and Fabrics, 7, $11-16$.

[4] Lau, K.W., \& Dias, T., 1994, Knittability of High modulus Yarns. Journal of Textile Institute, 2, $173-190$.

[5] Knapton, J.J.F., 1966, A study of the mechanism of loop formation on weft-knitting machinery, Part II : The effect of yarn friction on yarn tension in knitting and loop formation. Textile Research Journal, 36, 1081 - 1091.

[6] Ben Abdessalem S., Ben Abdelkader Y., Mokhtar S. \& Elmarzougui S., 2009, . Influence of Elastane Consumption on Plated Plain Knitted Fabric Characteristics. Journal of Engineered Fibers and Fabrics, 4, 30-35.

[7] Ben Abdessalem S., Elmarzougui S., Mokhtar S. \& Heni R., 2008, Parameters Influencing Plain Knitted Fabric Spirality. Indian Textile Journal, 4, 29-34.

[8] Chen, Q. H., 2002, Relaxation shrinkage characteristics of steam - ironed plain knitted wool fabrics. Textile Research Journal, 72, 463 - 467.

[9] Muhammet, U., 2013, Ultrasonic Washing Effect on Thermo Physiological Properties of Natural Based Fabrics. Journal of Engineered Fibers and Fabrics, 8, 39 - 51.

[10] Lau, K., W. \& Dias, T. Knittability of High-modulus Yarns, 1994, Journal of Textile Institute, 85, 173-190.

[11] Savci, S., Curiskis, J. I. \& Pailthorpe, M. T, 2001, Knittability of Glass Fibre Weft-Knitted Preforms for Composites, Textile Research Journal, 71, 15-21.

[12] Ozturk, M., \& Uygun Nergis, B., 2008, Determining the dependence of colour values on yarn structure. Color Technology, 124, 145 - 150.

[13] Banerjee, P.K., \& Bhat, P., 2006, Influence of yarn torsional rigidity on dimensions of cotton knitted loops. Indian Journal of Fibre and Textile research, 31, $409-414$.

[14] Roy, S. C., \& Banerjee, P. K.., 2000, Some preliminary investigations into the mechanics of 1x1 rib loop formation on a dial and cylinder machine, Indian Journal of Fibre and Textile research, 25, $97-107$.

[15] Alenka Pavko-Cuden \& Franci Sluga, 2015, Measuring loop lengths of elasticised knitted fabrics. Journal of textile institute, 106, 225-235.

[16] W. Choi \& N. B. Powell, 2008, The development of specialized knitted structures in the creation of resist-dyed fabrics and garments. The Journal of Textile Institute, 99, 253-264.

[17] Mumtaz H. Malik \& Tanveer Hussain., 2011, Effect of percentage of short fibers removed from cotton during spinning on the properties of dyed polyester/cotton blended knitted fabrics. Journal of textile institute, 102. 70-76.

\section{AUTHORS' BIOGRAPHY}

Zouhaier ROMDHANI, doctor and university teacher in textile engineering and laboratory member of Interfaces and Advanced Materials LIMA (faculty of Science of Monastir)

Sabri HALAOUA, doctor and university teacher in textile engineering in Engineering High School of Monastir and laboratory member of Textile Materials and Process Research Unit, ENIM, University of Monastir

Mohamed HAMDAOUI, Master Conferences teacher in textile engineering in Engineering High School of Monastir and laboratory member of Textile Materials and Process Research Unit, ENIM, University of Monastir 